Boise State University

ScholarWorks

University Author Recognition Bibliography: 2011 -

2012

The Albertsons Library

$11-1-2012$

\title{
Presence in Context: Teachers' Negotiations with the Relational Environment of School
}

Vicki Stieha

Boise State University

Miriam Raider-Roth

University of Cincinnati 


\title{
Presence in Context: Teachers' Negotiations with the Relational Environment of School
}

\author{
Vicki Stieha \\ Boise State University \\ Miriam Raider-Roth \\ University of Cincinnati
}

\begin{abstract}
This inquiry research builds on the theory of presence in teaching (Rodgers \& Raider-Roth, 2006) adding nuanced understandings of how school contexts play into teachers' abilities to support students' learning. Findings are drawn from multiple interviews with five veteran middle school teachers, teachers' written work, and field observations. Illustrating these findings is the compelling story of an exemplary teacher's negotiations of her practice in response to the school's relational environment. Our findings point to the teacher's sense of isolation and vulnerability-indicators of the relational context in the school as a threat to undermining her presence. They also create a compelling argument for the importance of a healthy relational context to support teachers' most powerful teaching, hence students' learning.
\end{abstract}

"I just...I do feel like sometimes that I am like in a little boat alone. And I'm not sinking. I'm rowing just fine, but I'm rowing really hard. And a little wind in my sails wouldn't be unwelcome. You know.” (Tamar, 3/2009) ${ }^{1}$

Meet Tamar, a seasoned and skilled teacher who is actively seeking feedback on her teaching. She hopes that she might gain "a little wind in her sails" if the school principal would come to her classroom, observe her teaching, "make a useful comment" or perhaps to "be another set of eyes." This simple desire is embedded in a complex relational web that makes fulfilling this need difficult.

This brief vignette represents the essential question guiding this study: How does the relational web of school shape teachers' capacities to implement innovative practice? To address the question, this article reports on a sub-set of findings from a two year research study which followed the trajectory of five veteran middle school teachers' thinking about their teaching and explores the ways that the relationships and contexts of the school can support and undermine teachers' practice (Stieha, 2010). Picking up their story almost two years after the teachers were engaged in a week-long Summer Teachers Institute (Institute), the study focused primarily on stories of teachers' practice. Considered in the contexts that hold them-a small independent Jewish day school-the participants' narratives present a compelling argument for the importance of a healthy relational context to support teachers' most powerful teaching, hence students' learning.

To illustrate the workings of the relational web in school, this article focuses on Tamar, one of the five teachers involved in the study. ${ }^{2}$ We build this analysis using Patton's notion of a "critical case" (Patton, 2002) to exemplify the findings. Although all of the teachers' stories are compelling, Tamar's story is especially rich in detailing the dynamics of relationship that impact her practice. Inspired by Sara Lawrence-Lightfoot (1997), we trace our findings through a singular storyline permitting us illuminate "resonant universal themes" by focusing on the particular (p. 14).

Internationally, the public discourse of educational policy focuses on standards, accountability, standardized curricula and shifting expectations for teachers while highlighting teacher learning as essential to student learning outcomes (Darling-Hammond et al., 2003; Fitz, 2003; Koshoreck, 2004; Lam, 2005; Timperley \& Phillips, 2003). This conversation, however, tends to ignore the centrality of teaching-learning relationships. Yet, it is clear that both

\footnotetext{
${ }^{1}$ All identifiers in this paper have been replaced by pseudonyms.

${ }^{2}$ The larger study, Understanding the Place of Collaborative Text Study in Teachers Learning and Practice has included three teacher cohorts to date (2007, 2009, and 2010). The 2007 cohort data informs this study.
} 
practicing teachers and students are alert to the consequences of trustworthy learning relationships or the lack thereof (Gidseg, 2007; Raider-Roth, 2005; Reichert \& Hawley, 2009). Our stance in this article rests on the assumption that healthy, growth-enhancing relationships are central to human development (Gilligan, 1996, 2011; Miller \& Stiver, 1997). Fundamentally, the quality of human connections can support teachers' continual growth and development as practitioners.

It is widely agreed that transferring teacher learning from professional development into change in practice and the possibility for enhanced student learning requires ongoing structures of support in the school culture (Adler, Rougle, Kaiser, \& Caughlan, 2003; Darling-Hammond, et al., 2003; Fullan, 2007a, 2007b; Huziak-Clark, Van Hook, Nurnberger-Haag, \& Ballone-Duran, 2007; Peterson, McCarthey, \& Elmore, 1996). In a similar vein, Cohen and Ball (2001) assert the importance of attending to innovation in a manner that goes beyond injecting a particular pedagogy or strategy into a school and expecting it to take hold. They criticize the dominance of interventions that only focus on "one element of the complex dynamic of instruction" explaining that "few intervene directly on the multiple elements of instruction - teachers, students, content, and the environments - and their interactions" (Cohen \& Ball, 2001; p. 77). This more holistic approach suggests a school culture plays a role in teachers' change of practice (Hargreaves, 2010). These researchers and others (e.g. Achinstein, 2002; Ancess, 2000; Gamoran, Secada, \& Marrett, 2000; Lam, 2005; Reynolds, Murrill, \& Whitt, 2006) suggest that educational change is a dynamic and multifaceted phenomenon and that tender balances between many variables are required to support teachers as they strive to improve student learning outcomes. With this research on teachers' professional learning as a background, we turn to the theoretical frameworks on which this analysis is based.

\section{Review of Scholarly Literature}

This study adds greater understanding to the ways that the teaching context plays into the critically important connections that practicing teachers have with students, content, pedagogy, and also with self. In order to explain these findings we draw together two theoretical frames: systems theories and relational theories. Because we are concerned with the contexts of the school for teaching and learning, a systems view is helpful. We see the intricately woven parts of the system playing onto one another within the school. Our question also requires that we look more deeply into the context and investigate the nature of the relationships within a school's systems-hence we turn to relational theories within the human development literature. Finally, this research expands upon a particular relational theory - the theory of presence (Rodgers \& Raider-Roth, 2006). In this section we will describe the frameworks that guide our work in more detail.

\section{Systems Theory and the School Context}

Systems perspectives provide helpful lenses when considering teachers' positions in school organizations. Indeed, several significant studies have applied systems approaches to such questions. We note the tendency to look broadly at the teacher within the organizational system (e.g. Fullan, 2007; Pace \& Hemmings, 2007; Sarason, 1996) or narrowly at the teachers' own development (e.g. Fessler, 1995; Guskey, 2002; Weasmer, Woods, \& Coburn, 2008). Fewer studies consider the organizational system as well as the sociological and cultural dynamics affecting relationships and learning in school. Pianta (1999), however, approached his educational research study with the student at the center of the system. He offers this explanation of applying general systems theory (GST) to schools stating that it helps "emphasize understanding the behavior of the system's parts in relation to the unit as a whole and understanding the dynamic properties of the whole in relation to its context” (Pianta, 1999, p. 24). In our extension of Pianta's theory, a teacher's behavior can similarly be explained by her interactions with other teachers, with students, and with administrators - all of which are dynamic properties of the whole system.

In Pianta's work, the "system is the key unit of analysis" (Pianta, Stuhlman, \& Hamre, 2002) whereas in this study, the individual in relationship is the unit of analysis. Epistemologically, when shifting the focus to the individual in relationship we are establishing a basic construct of feminist research. Such an approach captures the "interdependent" and "dynamic" interactions between individuals and others as well as between "person and environment." creating a framework that is constructivist and has an "emphasis on holism, personal meaning, subjectivity, and recursiveness between influences” (Patton, 2007, p. 40).

We argue here that a relational approach, which considers the teacher in relationship to others in the micro-system of the school, holds the potential for understanding the dynamics of teaching and learning that are at work in this 
research study. Others (e.g. Sarason, 1996; Senge, Scharmer, Jaworski, \& Flowers, 2005) have suggested that combining systemic or contextual variables with interpersonal variables provides a valuable lens into the general and particular dynamics of educational change. These suggestions, however, stop short of positing a particular framework through which to link these variables.

Given the teacher's centrality in this research study, the theory of a relational web (Stieha, 2010) provides a useful extension of systems models. This particular systems theory is structured upon feminist relational theories, which will be discussed in the following section, and can be understand as a relational system theory. The relational web helps us see the teacher's professional life as an interconnected system built upon relationships with others (e.g. students, classes, administration). These relationships can be conceived as links a web-like network that radiates out from her as the center of the web. Closest to the center are her relationships with "self" and with her own pedagogies and content knowledge. Moving outward are the relationships with individuals -dyadic relationships (e.g. with the principal, a peer teacher, a single student). Still farther are the relationships with groups (parents as a group, classes of students rather than a single student-teacher relationship), within the school (her relationship with the larger curriculum and the school's mission), and finally with the school itself. This conception of nested layers (see figure 1) echoes Bronfenbrenners's (1979) ecological model. Indeed, we share with Bronfenbrenner the notion that the contexts surrounding people are important human development variables. In this work, we are closely examining the nature of the relationships within nested and contexts.

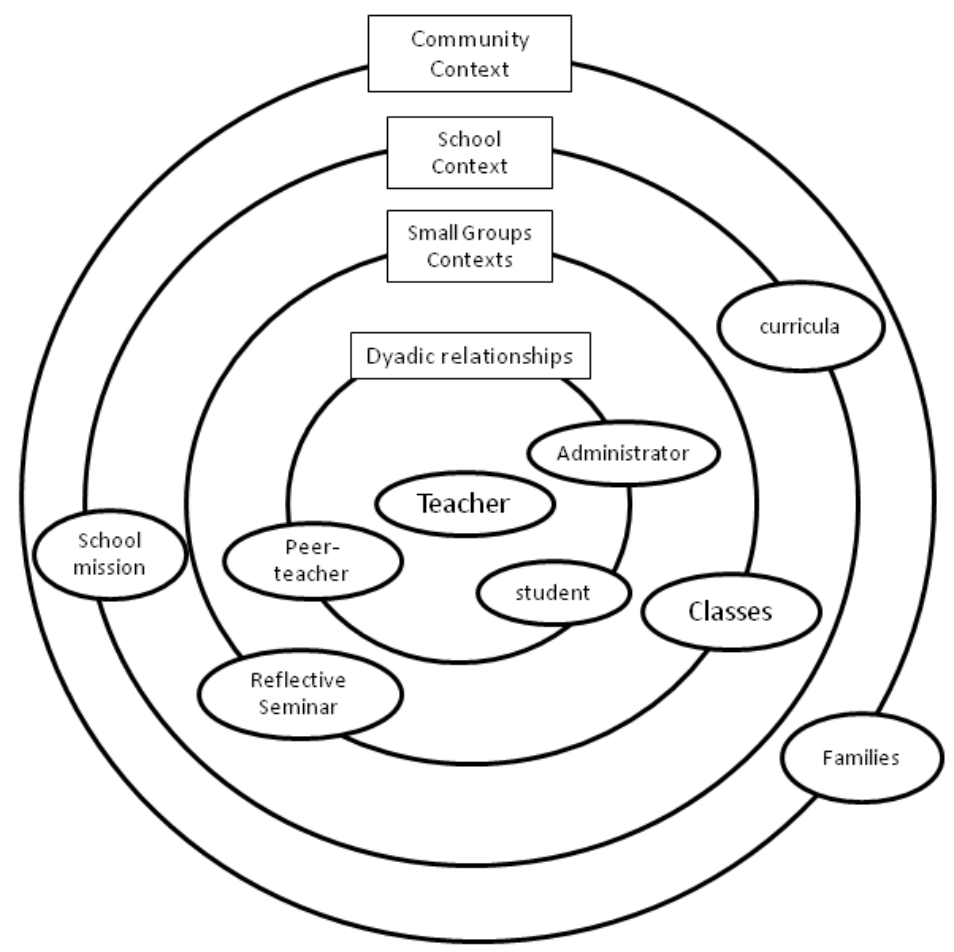

Figure 1. An illustration of the nested system of relationships in a school context.

While individuals simultaneously participate in multiple relationship systems, in this discussion we will limit our focus to the system of the teacher's school life, as it is illustrated in the figure above. The idea of systems thinking opens the door for inquiry into the way that these relationships can play into teachers' practice. To support a discussion of that inquiry, we turn to our application of "relational theory."

\section{Relational Theory}

With the elements of systems theory and the relational web (Stieha, 2010) discussed above, we now turn to the second guiding theory for this research — that is, relational theory. Although we say relational theory here, we are in actuality referring to a theoretical framework that is grounded in the work of Carol Gilligan $(1982,1996,2011)$ and 
the Wellesly Centers for Women, principally that of Jean Baker Miller and Judith Stiver (1997), both of which developed at approximately the same time. These theories added "a different voice"-the voices of girls and women-to the human development literature (Gilligan, 1982, 2011). Often discussed as feminist relational theories, these theories "share a notion that psychological development is fostered and impeded through relationships” (Spencer, 2000). In our research we join numerous studies (Chu, 2000; Hensley, 2009; Noddings, 2003; Raider-Roth, 2005; Raider-Roth, Albert, Bircann-Barkley, Gidseg, \& Murray, 2008; Reichert \& Hawley, 2009; Spencer, Porche, \& Tolman, 2003; Way \& Chu, 2004) that have convincingly demonstrate the applicability of feminist relational theories to educational questions.

As we apply this theoretical framework to this research study, we employ Miller and Stiver's (1997) language of relationships. Specifically, Miller and Stiver (1997) characterize connection in relationship as "interaction between two or more people that is mutually empathetic and mutually empowering," and "disconnection to mean an encounter that works against mutual empathy and mutual empowerment," (p. 26). Thus, as we discuss connected relationships in this article we understand them as mutually empowering - or growth fostering for both parties. A second quality of the interaction, mutual empathy indicates a quality of being "with" the other in thinking, feeling, and action (Miller \& Stiver, 1997).

We understand that relationships can also be described as "disconnected" or lacking mutually empathic and empowering qualities. There are disconnections that are not simply the absence of connection, but are the result of a particular "strategy of disconnection," a state that Miller and Stiver (1997) label the "central relational paradox." This state, called a "brilliant but costly solution" by Gilligan (1996, p. 244) is a move to disconnect the self from relationship (with another person or with some aspect of the self). This move emerges when an individual feels relationally vulnerable and involves paradoxically sacrificing one central relationship in order to protect another. Although it is self-protective in nature, it carries a significant cost because it can inhibit a person's ability to confidently know what she really does know (Gilligan, 1982, 2011). We understand that this relational dance is continuous. Relationships are not static and disconnections, whether momentary or more prolonged, happen. It is, however, the process of repair that builds understanding and contributes to growth in relationship (Jordan, 2001; Miller \& Stiver, 1997) and learning (Raider-Roth, 2005; Stieha, \& Hensley, 2012).

\section{Relational Trust in the School Context}

One of the variables on which relational balances rely is trust. Within the relational literature, particularly that which closely examines the school environment, there is an essential conversation around trust. In order to open classroom doors for teachers' meaningful connections to others and to deepen teacher conversations beyond the mundane, there must be an atmosphere of trust to serve as the "connective tissue that binds individuals together to advance the education and welfare of students” (Bryk \& Schneider, 2003, p. 44). The process of establishing and supporting an atmosphere of trust in a school requires continual effort and attention as well as an ethic of care, neither of which appear to be naturally occurring in school organizations (Bryk \& Schneider, 1996, 2003; Slater, 1996). Ironically, trust and care are noted in the literature as crucial for sustaining a community of professionals (Bryk \& Schneider, 2003; Lam, 2005; Lieberman \& Miller, 1999; Sebring et al., 2006) and fostering teachers' and students' confidence to trust their own knowledge (Raider-Roth, 2005). Thus, an essential element of a healthy relational context, one that has numerous robust relationships, includes relational trust. With this concept established, we turn to a particular relational theory that has been previously applied to teaching and learning - the theory of presence (Rodgers \& Raider-Roth, 2006).

\section{Having Presence}

The centrality of relationships in the learning process has been theorized in detail by Rodgers and Raider-Roth (2006) in their discussion of presence. They define presence as:

a state of alert awareness, receptivity and connectedness to the mental, emotional and physical workings of both the individual and the group in the context of their learning environments and the ability to respond with a considered and compassionate best next step. (p. 266) 
Describing the "dimensions of connection" Rodgers and Raider-Roth (2006) draw upon the relational concepts discussed above (e.g. connection, disconnection, and relational trust) and suggest that the contexts or environments for teaching and learning play a role in supporting and undermining presence in teaching. A school context that is rich with relational trust (trust in one's self as well as others, and a sense of being trusted by others) is an important component to building and maintaining presence in teaching. Additionally, the contexts for teaching and learning play a role in supporting and undermining presence in teaching; "teachers need to know and to trust themselves and they also need to know and trust their students and the contexts in which they work" in order to sustain presence (Rodgers \& Rodgers \& Raider-Roth, 2006, p. 283).

This conception of presence differs from others who consider social presence in light of modern technology (Short, Williams, \& Christie, 1976; Tu \& McIssac, 2002), explore social and emotional presence for online teaching effectiveness (Anderson, Rourke, Garrison, \& Archer, 2001; Aragon, 2003), or in organizations (Senge, et al., 2005). Whereas these notions of presence are one or two dimensional, the theory of presence in teaching as Rodgers and Raider-Roth have described it is three dimensional—it considers the cognitive, affective, and relational aspects of presence.

Reminding us that a "key aspect of presence is being present to oneself," Rodgers and Raider-Roth (2006) highlight both threats to presence (e.g. tension between personal and professional selves) and ways to foster presence (e.g. "critical self-awareness"), noting these processes are ongoing (p. 271). Changing expectations within the teaching context can certainly be seen as triggering tension between the personal and teaching selves. For instance, if the culture of a school creates pressure to silence or hide a central aspect of the teacher-self (e.g. content knowledge, pedagogical knowledge, or teaching philosophy) or the personal-self (e.g. relationship status, religious or cultural identification, illness), such a move can initiate a central relational paradox, as discussed above, for the teacher. Essentially, this move may diminish presence as a teacher who is fully connected to herself "is able to bring his whole self to attend to the learning processes of his students by seeking to 'extend' their powers, helping them to construct their knowledge" (p. 273). In their theoretical framework, then, the authors specify the teacher-self, teacher-student connections as fundamental to presence.

\section{Research Methodology}

Our methodological approach throughout this research study is guided by the relational theories we have just discussed. From the constructivist and collaborative design of the Summer Teachers Institute, to the modes of data collection, and through the analysis and presentation of the findings (all of which are described below), our stance is relational. Additionally we attended closely to our own presence as we considered the dynamics of relationships that exhibited themselves in the settings and interactions described in this research study.

\section{The Summer Teachers Institute}

The Summer Teachers Institute — a five day professional development seminar designed for veteran teachers—is the foundation for this inquiry research (Cochran-Smith \& Lytle, 2009) as it launched our examination of the place of "collaborative text study" ${ }^{3}$ in the teachers' learning and practice. The focus of the Institute was to deepen teachers' understandings of Jewish culture and civilization through the examination of primary texts. An assumption of the Institute design is that the process of this culturally immersive learning experience would provide pedagogical approaches for teaching about non-majority cultures through a close study of their texts, artifacts, and modes of interaction. The Institute was a model of relational teaching and learning and we delved deeply into these dynamics, which we see playing out in the narratives of practice that followed the institute. The structure of the Institute invited the teachers to take responsibility for their own and their peers' learning (Raider-Roth \& Holzer, 2009), setting the stage for our inquiry into what that learning experience felt like for the teachers as learners, as teachers, and how they translated their experience in their own classrooms.

\footnotetext{
${ }^{3}$ The collaborative text study model adopted at the Summer Teachers Institute was developed by the Mandel Center for Studies in Jewish Education, which curricularized particular practices including attentive listening, attentive questioning, voicing, and challenging (Raider-Roth \& Holzer, 2009).
} 


\section{Participants}

The findings in this paper are part of a five year educational action research study into teachers' learning and our own professional practice as teacher-educators, which has included three Institutes between 2007-2010 and almost 50 teachers from a wide variety of public, private, and parochial schools throughout the U.S. ${ }^{4}$ Because we are interested in the question of how a single school context plays into a teacher's ability to remain present to her teaching and her students learning, we focused on teachers in the 2007 Institute cohort, who hailed from one Jewish Day school, (Meir School). These teachers (Hadassah, Tamar, Sarah, Nancy, and Sally) were chosen for the follow up study because they share a group of approximately 30 middle school students in grades $6-8$. After a preliminary analysis, we chose to focus on Tamar, a middle school language arts teacher, as a "critical case" (Patton, 2002) to illustrate the findings.

The analysis for this paper is informed by three sets of semi-structured interviews, field observations in the teachers' classes over a three week period, observations during the Institute, and teachers' written reflections. The research questions underlying this study began in 2009 when Vicki was observing the teachers at Meir School, and noted their practices and the relationships in the classroom. Relying on field notes, Vicki later asked the teachers to talk about particular teaching moments (moments that Vicki suspected illustrated what Rodgers and Raider-Roth defined as presence) so that they could share their perspectives of the experiences. In addition to moments of presence, Vicki wondered about the absence of presence (again based on observations and narrative data) and the relational aspects of that dynamic as well.

\section{The Listening Guide}

Our initial analysis of presence narratives were then compared to our understandings of connection and disconnection informed by the relational theories described above. The centrality of relationships and (dis)connection led us to select the Listening Guide (Brown \& Gilligan, 1992; Gilligan, Spencer, Weinberg, \& Bertsch, 2003) as our analytical method for the interview data. The Listening Guide attends closely to the participant's voice as it expresses the psyche in the "ever-changing...sense of self and the experience of relationship" (Brown \& Gilligan, 1992, p. 23). As we discussed above, relational theory draws largely upon Carol Gilligan's (1982, 2011) groundbreaking work regarding the centrality of voice in human development. Born of a need for a research method that did not insist upon distance and objectivity, the Listening Guide opens up spaces for the participant to "speak in her own voice" and for the researcher to "bring [her] own knowledge...into relationship with [her] work” (Brown \& Gilligan, 1992, p. 15).

The Guide is widely used by researchers seeking a relational stance with their participants' explorations into "matters of the self" (Dillon, 2010, p. 16), and "aspects of identity" left "underexamined" by traditional methodologies (Estrella \& Forinash, 2007, p. 378). Indeed a growing number of researchers (e.g. BeauboeufLafontant, 2009; Gidseg, 2007; Hensley, 2009; Way, 2001, 2011) are linking relational theories with this relational research methodology.

Examining the interview data with The Listening Guide involves listening and reading narrative data in four or more distinct stages. The first listening is thematic, attuning to the dominant ideas, the flow of the conversation, and the stories that emerge. In our process the ideas of self in relationship to other teachers, students, administrators, and to self were highlighted during this listening so that we could return to them in subsequent listenings. The second "listening" attunes closely to the voice of the self by focusing on the first, second, and third person pronouns (I/we, you/he/she, they/them) with their accompanying verb phrases and then extracting and arranging these sections of narrative in "voice poems," preserving the order of the phrases as they occur in the narrative. This listening brings the researcher closer to the participant as he or she speaks of the self in relationship through his or her voices of self (thinking, feeling, and doing). During this listening we take note of shifts from first person to second person voices, as well as the loss of a personal voice, or variations from typical speech patterns (e.g. a shift to more hesitant or faltering voice, "um" or "uh" in a particular section of the narrative, but not throughout it) as these may be dissociative moves. Such moves may suggest a relational distance for the speaker and provides a marker for our deeper analysis into these passages. The third and fourth listenings, also called "contrapuntal listenings," are

\footnotetext{
${ }^{4}$ The larger study has IRB approval under the project name, Understanding the Place of Collaborative Text Study in Teachers Learning and Practice.
} 
arranged in voice poems as well. These poems focus on the central tensions in the narrative as they come together and diverge, allowing us to pay careful attention to the ways these voices play out against one another.

The voice poems in the second, third and fourth listenings are crucial data sources throughout the analytical process; at the same time, we share with others (e.g. Dillon, 2010; Estrella \& Forinash, 2007; Gilligan, 2002, 2003) the practice of using poems sparingly in written findings, largely due to space limitations. As we move from poetic verse into the manuscript representing this analytical process, we create a synthesis that draws a conduit between the participant's "inner and outer world" rendering it visible to the researcher (Gilligan, 1996, p. 253) as the participant's voice speaks to the research question. As Cahnmann (2003) asserts, "incorporating the craft, practice, and possibility of poetry in our research enhances our ability to understand classroom life and support students' potential to add their voices to a more socially just and democratic society” (p. 34).

\section{Complementary feminist relational methodologies.}

We note that the first listening described above resembles features of feminist grounded theory (Doucet \& Mauthner, 2008) as we listen for themes to emerge from the narrative rather than applying them a priori. We extend the use of this complementary feminist methodology in the analysis of our field observations and our research logs. Using a recursive process, we continuously wrote memos documenting our questions, and inviting contemplation of the voices that did not seem to fit "neatly" into our developing theories. Finally, we solicited the input of our study participants regarding these findings and invited their comments on the resonances and dissonances they found in our interpretations (Clarke, 2007; Tappan, 2001). These processes reflect the collaborative and non-linear application of feminist grounded theory (Clarke, 2007).

\section{Research as insider-outsiders.}

In addition to mindfully selecting methods that are consistent with our research philosophy, as feminist qualitative researchers, we place ourselves and the subject matter in the "same critical plane" (Harding, 1987, p. 9). Doing so, we have explored (through critical reflection and memos as well as through our inquiry community) our own positionalities during our research and analytical processes. As we have explained, this research follows a particular professional development experience, the Summer Teachers Institute, which Miriam co-facilitated and during which Vicki's role was resident researcher. Miriam also led a monthly teacher inquiry group at the school, the Reflective Seminar, ${ }^{5}$ which gave her immediate knowledge of the teacher's professional lives and contributes to our understandings of these data. Finally, since her children were enrolled in Meir School during the study period, Miriam's roles and relationships with the teacher-participants were multiple and required continual negotiation. Vicki, although she was involved throughout the study and developed a closeness with the teachers, had more of an "outsider" relationship them. We see these positionalities as complementary, giving us an insider-outsider perspective and provide depth to our analysis (Cochran-Smith \& Lytle, 2009; Drake \& Heath, 2008; Humphrey, 2007).

\section{Findings}

\section{Seeing Presence}

We begin these findings by looking closely at Tamar, a creative and energetic Language Arts teacher, discussing the interactions she has with her students. We refer to her as a veteran teacher for she has been teaching fourth through eighth grades at Meir School for over 12 years. Continuously seeking ways to help her students learn, Tamar attended our Summer Teachers Institute in 2007 and then participated in a Reflective Seminar for teachers that Miriam led at the school for two years. Speaking about curriculum, pedagogies, and her students, Tamar says, "I'm really not satisfied unless they're really thinking. Um, so I'm constantly searching for new things I can do with them" (6/2007; L. 205-206). During the first interview with Tamar in June of 2007, she exuded confidence about her teaching:

\footnotetext{
${ }^{5}$ Full descriptions of the Summer Teachers Institute and the Reflective Seminar can be found in Stieha (2010) and (Raider-Roth \& Holzer, 2009)
} 
I can teach them how to write an essay - I can teach them how to write a good essay - I can teach them things they might not get until high school if they are ready to get them. So, I feel confident there. (6/2007; L. 205-217)

Listening to Tamar's "I voice" in the opening of this passage her confidence is unambiguous:

I

I can teach them

I can teach them

I can teach them

I feel confident

Pulling the voice of Tamar's teacher-self away from the surrounding language leaves us the bold statement, "I can teach them," repeated three times. Her actions are affectively positive ("I feel confident") and her action is clearly linked to her students. Her focus is not on the content or her own pedagogical content knowledge; rather it links that knowledge to the student ("I can teach them how" and "I can teach them things" - emphasis added) and determines the "things" based on the students' readiness. When we analyzed the interview transcript from this first of three interviews with Tamar we coded this as a narrative of presence noting many more sections that reinforced this behavior as a pattern. Additionally, in this data we see strong evidence of the individual, Tamar, in relationship with her pedagogical systems and in relationship with her students (I can teach them...I can teach them...I feel confident). We read her account as empowered and connected.

The second interview with Tamar took place a few months after Tamar's return to Meir School in the fall of 2007 following the Institute. In that interview she explained that she had woven several ideas from the week we spent together into her teaching. Describing her "major learning" from the Institute, Tamar responded that she left with a deeper understanding of what it means to learn cooperatively. In addition, Tamar commented that after the Institute she was, "looking for opportunities to bring in something Jewish [into her curriculum] just because it's Meir and it's worth doing." Tamar decided to experiment with collaborative text study as an enhancement to a unit featuring Karen Hesse's (1997) novel, Out of the Dust. Picking up on the Biblical title allusion, Tamar went back to the story of Adam and Eve and wove it into her lesson for the novel. She explains that the students' close study of the Garden of Eden text helped them draw more meaning from Hesse's story, and they made "huge connections" which they "would have never made," leading to powerful learning. Out of the Dust, which takes place during the Dust Bowl, traces the tragedies of a fictional family struggling to survive on the Oklahoma plains. Tamar explains that her students were able to link the characters being "ecologically irresponsible" and then "being punished for having wrecked [the land]" to their study of environmental responsibility and, she adds, "the best writing the kids did was their explanation for that chain of events." As Tamar reflects on their learning as a class she does so in a voice that places her own learning on the same plane as that of the students. She explains the lesson the class took away from their work:

[Y]ou know, you get this gift from God, you don't appreciate it, you wreck it, and then you're stuck in the dust bowl. And it was-I would never have gotten there. I mean, I hadn't even really gotten there myself, but we got there together. (10/2007; L. 164-167)

As Tamar describes this powerful learning experience we focus closely on a point when her voice shifts from talking about the book to talking about the learning:

$\underline{I}$

I would never have gotten

I mean

I hadn’t even gotten $\underline{\text { We }}$

We got there 
Examining the brief passage as a voice poem Tamar acknowledges that she had not found the meaning on her own ("I would never have gotten," "I hadn't even gotten"). As her voice shifts from first person singular to plural ("we got there together”) she gives us compelling evidence of her presence in teaching and of her students' learning as she links their collaborative thinking, feeling, and doing with one another.

Other stories of Tamar's presence in teaching emerged during Vicki's field observation at Meir School. For instance, referring to a lesson Vicki had observed, Tamar recounts two of the students' oral presentations during a lesson. Tamar notes the ways in which a typically quiet young girl finds her "voice" saying, "that was huge for her to get up and, you know, have a voice. And even her body language was just a little bit, you know, just more aggressive. It was excellent" (field notes, 2/2009). As she went on to reflect on another student's presentation, Tamar reveals how she was "feeling with" (Miller \& Stiver, 1997) her students as they stretched and grew through their learning. Concluding our conversation, she says, "It was cool, it was really cool. I was very pleased to see it" (field notes, 2/20/2009). This story demonstrates the mutual connection Tamar has with her students.

In addition to these examples drawn from Tamar's teaching practices, there were other striking moments of presence that teachers either shared through narratives or Vicki observed at the school. There were also many stories that revealed how teachers' presence could be undermined by a sense of isolation, invisibility, or vulnerability in the school. First we will look at Sally's narrative and then return to Tamar's to explain this dynamic.

\section{Feeling Disconnection}

Tamar's narratives described above emerged from the first and second set of interviews which took place in 2007. The third set of interviews and observations took place during a follow up study in 2009. As we listened and analyzed these interviews, we were struck by a dominant theme of disconnection that emerged-including voices of isolation from other teachers, from administrators, and from parents. It was voiced as "invisibility" and carried a sense of vulnerability (Stieha, 2010). As we peel the layers of these stories away, we see a very complex relational dynamic. In order to see the changing relational context in which Tamar existed in 2009, we begin by listening to the voice of Sally, the principal at Meir.

\section{The principal-teacher relationship.}

A new Head of School ("David”) arrived at Meir School in 2008, stepping into an institution experiencing financial strain partly due to falling enrollment over many years and partly to the recent economic downturn. Added to the financial pressure in the school were the "adjustments" to new leadership and a mission that had been revised the prior year. In short, 2007-2009 were complicated years for Meir School as a system. We take these facts into consideration when we seek an understanding of how tension in one part of the system plays out in another. The reverberation of system stressors is captured in the theory of the relational web, discussed above. In that discussion we suggested that relational disconnections in one area of this web-like system can play out in other areas of the system. For example, as Sally, the principal, was adjusting to David, her ability to be present to the teachers was sacrificed. $^{6}$ In her interview, Sally shared, "a new head of school is always going to make staff nervous-I'm nervous. You know, you don't know, well will the new boss like me, will the new boss think I'm worth keepin' around?” She continues:

And things...I would say that the culture is more tense right now than - you know the individuals are more guarded and more tense and more worried about their continued employment, um, which is impacting their practice in ways that are probably pretty unhealthy. [V: $\mathrm{mmm}$ ] Uh, it wasn't always so. [V: yea] And it won't always be so. But, I'm going to probably be down $2 \frac{1}{2} 2$ FTEs next year, plus David is cutting on the other side of the aisle. People are going to lose their jobs. Or lose a part of their job. Because we don't - if we don't have the kids you can't sustain. (3/2009, L. 342-347)

\footnotetext{
${ }^{6}$ In Meir School, the principal is responsible for curriculum and instruction at the school. She reports to the Head of School.
} 
In Sally's comments we can hear the disconnections that are developing in the school context. Listening to the narrative in a voice poem reveals the stark absence of relational connections:

$\begin{array}{llll}\text { I I would say } & \underline{\text { You }} & \underline{\text { They (their) }} & \text { We } \\ & \text { You know } & \begin{array}{l}\text { Their continued } \\ \text { Their practice }\end{array} \\ \text { I'm going to } & & \text { Their job } & \text { We don't } \\ & & \text { We don't have }\end{array}$

You can’t sustain

Sally's response reveals the nature of the school's context and the separation between herself and the teachers as she speaks of her staff. Interestingly, Sally starts by saying, "I would say" and then quickly inserts "you know" as if looking for confirmation from Vicki (Brown \& Gilligan, 1992). There is a tentative nature in her voice as she speaks of the current conditions surrounding the relationships in the school she does so in a voice that sounds protectively detached ("the individuals"). The relationships are strained by this "unhealthy" culture ("more guarded and more tense and more worried"). In the voice poem we hear relationships that are in a disconnected state as she flatly narrates what is happening in the school-it is a narrative of absence ("we don't have," "you can't sustain"). Further, Sally's connections to the teachers, the school or David at this point in time is unclear as only two I phrases appear in the passage. As we noted earlier in this paper, disconnections may be temporary and may vary in their severity. Where we had seen evidence of robust connections between Sally and the teachers in 2007 (comments such as "my team" and repetition of collective personal pronouns, "we" and "our") ${ }^{7}$ the pattern in 2009 had shifted to one of disconnection.

For her part, Tamar was aware of the pressure Sally was experiencing. She describes how David's coming to Meir affects the school:

So, it's probably changed things more for [Sally] than it has for everybody else. So I would say, I don't know, [David's] ....yea, it's changed because he's had one or two ideas that he's imposed on us, you know, that...um... in a way, not as much as I would have expected. (3/2009; L. 281-284)

We note the language that Tamar uses and the voice in which she speaks as indicative of an increasingly unhealthy relational environment. This voice is a stark contrast to that in earlier interviews as we note the qualified phrases ("I would say," "I would have expected") rather than confident assertions. As Tamar explains that David "imposes" ideas on the teachers, and on Sally, her voice is marked by uncharacteristic pauses, the "um" and she trails off leaving a topic that could make her vulnerable if she were to elaborate. As we discussed earlier in this paper, relational disconnections can undermine mutual empathy and empowerment (Miller \& Stiver, 1997), rending the relational web. In this instance we see evidence of ruptures in the relationships between Tamar and David, between Sally and David, and we can reasonably wonder the impact that such ruptures have on the overall web of relationships and Tamar's ability to remain present to her teaching and her students' learning.

In the opening of this paper we shared Tamar's comment that she was looking to the school's leadership for "another set of eyes" or a little "wind in her sail." She returns to this theme of teacher-administrator relationships in a narrative that clearly traces the disconnections she is experiencing. Tamar explains that previously at Meir School:

The teachers were treated more respectfully. Their opinions were solicited more routinely, when they were building the calendar for the next year, there were teachers who [V: ok] who represented all of the teachers, who brought our opinion and that, that all ended. And, and now there are no teachers who have any input in any kind of planning. So... (3/2009; L. 290-295).

\footnotetext{
${ }^{7}$ See Raider-Roth, Stieha, \& Hensley (2012), for a more detailed discussion of Sally’s connection to her faculty in 2007.
} 
Using a voice poem to view Tamar's voice in this narrative, the disconnection she is describing between the teachers and the administration is even clearer:

$\begin{array}{ll}\underline{\text { I }} & \underline{\text { Our }} \\ \text { I would say } & \text { Brought our opinion }\end{array}$

For our opinions

In our opinions
They

Their opinions

They were building

They are not great at asking

They're not real interested

The most striking features of this narrative are the absence of Tamar's first person voice and the back and forth tension between the first person plural and the third person plural voices as they play against one another. In this voice poem, what Tamar says and the voice in which she says it are consistent- she describes a divide and we see the divide between "our" (she and the teachers) and "they" (after the first "their opinions," they is the administration) in the voice poem. The context and the manner in which she speaks make it clear that Tamar is experiencing a relational disconnection with the "administration." Finally, the uncharacteristic repetition of words in her narrative ("who, who represented"... "that, that all ended") are striking indicators of the emotional weight of the passage and perhaps a reluctance to speak of it.

In addition to her sentiments regarding the teacher-administrator relationships, Tamar experiences another key relational rupture within the school's web-disconnections between teachers and parents. These disconnections are prominent in a narrative about her deeply felt disappointment over the parents' flagging support for the school. Although she repeats that "she doesn't take it personally" when students withdraw from the school, we can hear the loss of connection this triggers for Tamar. She says:

I would certainly love for the community to support the whole school in the sense that they send their kids here and we don't have to sweat it out every year. I mean, that's...there's a lot of anxiety about kids leaving and people not feeling like it's a good enough school, and...I, I'm...every year it's really hard. [V: $\mathrm{mm} \mathrm{hmm]} \mathrm{And} \mathrm{I'm} \mathrm{more} \mathrm{at} \mathrm{peace} \mathrm{with} \mathrm{it} \mathrm{now,} \mathrm{I} \mathrm{mean,} \mathrm{I}$ know that the economy is terrible and that it's not our fault. [V: yea] But, but it's kinda...demoralizing, to feel like you've worked your tuchus ${ }^{8}$ off and parents still aren't happy and are pulling their kids out. [V: yea] I can't work any harder. I mean, I know I can’t work any harder. (3/2009; L. 465-472)

As this excerpt opens, there is a tenuous balance between the notions of desire for community support and Tamar's identification with the school. The desire for parents to send their kids to the school every year as they have in the past is a desire for that connection. In reality, uncertainty surrounds the school. They have to "sweat it out," there is "a lot of anxiety," about parents' sense that the school is not "good enough"-all of which raise questions about the relationship between the school and some in the parent community. Noting the halting pattern in Tamar's voice in this narrative, we sense the intensity of the emotion behind the ideas she is sharing. Her voice here also suggests a lack of relational trust in the parents. Recall, that trust is sustaining element for community in schools (Bryk \& Schneider, 2003; Lam, 2005; Lieberman \& Miller, 1999; Sebring, et al., 2006) and has also been found as requisite to teachers' and students' ability to trust their own knowledge (Raider-Roth, 2005). These elements, in turn, cooccur with presence in teaching.

Following Tamar's voice in this passage about the school-community relationship makes it clear that the dominant ideas in this narrative are not firmly connected to her first person voice. We read this move as one suggesting relational distance (Gilligan, et al., 2003):

\footnotetext{
${ }^{8}$ Yiddish for rear end
} 


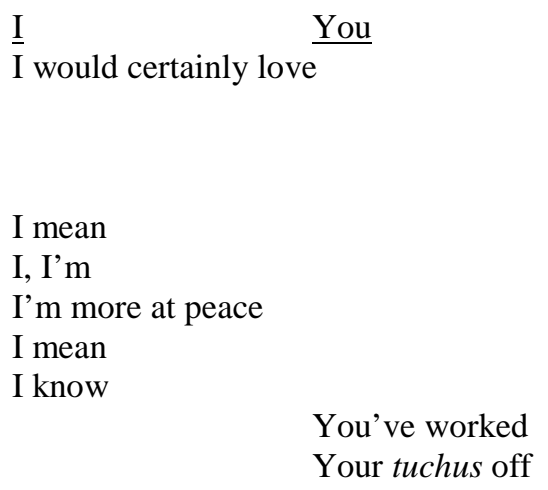

I can’t work any harder

I mean

I know

I can’t work any harder
We $\quad$ They

They send

their kids

We don't have to sweat

Reading the "I voice," we find a curious dissonance between the phrase "I'm more at peace" (we note the qualifier of "more" indicating that she is not fully at peace) and the subsequent repetition of "I mean" and "I know" phrases-a combination that repeats twice. Brown and Gilligan (1992) suggest that the "repeated tap of 'I mean'” may be an attempt to convey "her thoughts, her intellect, her feelings to her interviewer" (p. 128). We wonder if Tamar is telling us that she is still trying to find a way to be "at peace." Because she shifts from "I mean" to "I know" we hear the voice as emotionally unsteady - the intellect is clear as she knows the reason for the parents' disconnection, ("the economy...it's not our fault"). But knowing and feeling do not sit easily together here. A voice of despair emerges as an answer: "it's demoralizing." Tamar shifts into a dissociated voice (voiced as "you") that speaks of being "demoralized” despite having "worked your tuchus off.” No amount of work on Tamar's part seems enough to repair this disconnection (“I can’t work any harder. I mean, I know I can’t work any harder”).

This section of the narrative is marked by disconnection and suggests a breach in trust. Expanding upon the passage above, Tamar begins by talking about not having the "enrollment" they need as a school, commenting that she is grateful that she is "not the one that has to balance the budget." However, as she moves to speak about parents who "pull kids out" of the school, she says "you just want 'em to stay here and let us do our job." We note that her first person voice fades away as she speaks in a removed voice using either "you" or the collective, "we." Even the first person plural disappears as she speaks about children leaving the school:

Part of it is we used to have these parents who were very committed to sending their kids to Jewish school. [V: $\mathrm{mm} \mathrm{hmm]} \mathrm{And} \mathrm{so} \mathrm{it} \mathrm{wasn't} \mathrm{like,} \mathrm{they} \mathrm{didn't} \mathrm{question} \mathrm{the} \mathrm{decision} \mathrm{every} \mathrm{year.} \mathrm{The}$ kids went...once they made the decision to send their kid here, they were going to send them here until they were done. (3/2009; L. 475-478)

Despite Tamar's earlier assertions (“I'm more at peace...it's not our fault”... “I don't have to worry. If we have kids, I have a job"), the disappearance of her "I voice” in this narrative suggests her dissociation:

\section{$\underline{\text { We }}$}

We used to have

\section{They}

These parents who were very committed

They didn't question

They made the decision

They were going to send them

Until they were done

The disconnection between Tamar and the parents is made vivid by the voice poem for this passage. Her "I voice" completely disappears, despite her protest that she does not take it personally, when she says, "they pull them out." In the third person ("they"), Tamar echoes what Bryk and Schneider (2002) have described as a desire for organic trust. She recalls the past parents who were "committed" and did not "question," but "made the decision" to send 
the kids to this school "until they were done." In pulling their students out of the school because, "people are not feeling like it's a good enough school" they are breaking the trust that Tamar and other veteran teachers had come to believe in. Organic trust, the "notion of unquestioning beliefs of individuals in the moral authority of a particular setting," is common particularly in religious schools where there tends to be a stronger emphasis on school mission and a shared philosophy (Bryk \& Schneider, 2002). As a Jewish day school, parents in the past made a decision for their children to go there and "get every year of Jewish school that was possible until they had to go to high school" (Tamar, 3/2009). Bryk and Schneider (2002) argue that modern life undermines the pillars of organic trust and that "individuals are less likely to maintain life-long affiliations" than they once did (p. 16). Although the rationale for parents' decisions may perhaps be more than "modern life" interceding, the tension that we hear in this passage may point back to a larger pressure the school is facing as well-how to get parents to keep their kids at the school. Neither Tamar nor the school seems to have arrived at the answer. Tamar's voice clearly carries disappointment in this change and suggests a break in her relationship with the parent body at large (although not necessarily with "all parents”). As we indicated above, we aver that trust is requisite for empowering and empathic relationships

Indeed, despite what Vicki witnessed as highly engaged teaching and stories that speak of her presence to her students' learning, Tamar explained that changes in the 2009 school year made it hard to "be above average." There is simply not enough time, she explained, to give any more to her students and she comments that the level of her teaching inevitably suffers. Talking about the fragmentation she feels, Tamar reveals self-doubt about her teaching practice. "Every day I try to do 12 things. And it's hard [V: Right] And I'm always feeling really pressured and really frazzled and wondering if I do any of it well because I do too much, you know" (3/2009; L. 134-135). It seems, in light of the multiple disconnections that Tamar is experiencing in her school relational web, that she is sacrificing presence in her teaching practice to "do 12 things" that she does not have time to do. Despite her claim that she "has a job" and she does not "take it personally," her comments convey otherwise—she is affected by these systemic pressures. The relational juggling that Tamar is doing appears to be wearing away at her ability to be present in her teaching practice.

\section{Discussion}

By tracing Tamar's narrative across these interviews and observations in her classroom and school, we can see a clear picture of the way the relational context of the school has changed. We see the stark contrast in the narratives of presence in the 2007 interviews and challenges to presence in the 2009 interview. The analysis shows that, with the foundations for trust in transition in this school context, many of the relationships within the relational web are feeling the impact. For instance, the data very clearly demonstrate the daily tensions that are founded in the teacheradministrator relationships (so clearly highlighted by Tamar's desire to have "a little wind in her sails" or for teachers to contribute to the school calendar). Tamar's words remind us of that "to be in connection with another human being a person needs to see and be seen by the other" (Rodgers \& Rodgers \& Raider-Roth, 2006) - one of the essential elements for presence. We are struck by Tamar's desire to enhance her teaching by better understanding her students' learning and her clear sense that the relationship with Sally, the school principal, is a key to that growth. Being seen as member of the school community is also important as Tamar seeks to confidently know what is happening to the school in this uncertain economy. Her narrative of being "more at peace" and yet knowing she "can't work any harder" captures the ambiguity in her teaching life.

It is also clear that Tamar's relationship with parents, one which is central in her teaching-life, is marked by disconnection. Recall her comment, "I would certainly love for the community to support the whole school in the sense that they send their kids here and we don't have to sweat it out every year." In this section of the narrative we noted the emotionally heavy nature of Tamar's voice and saw the affective response that she had as a result of that disconnection. We are mindful that trust is an essential element in growth enhancing relationships and see stark evidence of a loss of trust in this school context.

Most concerning, however, is the resultant change in Tamar's teaching practice. Her description of "fragmentation," and her compromised sense of effectiveness in teaching, highlights the high-stakes consequences of an unhealthy relational context. Although presence can be difficult to pinpoint, "a teacher's pedagogy is the most visible aspect of presence” (Rodgers \& Rodgers \& Raider-Roth, 2006, p. 279). When Tamar tells us that her pedagogy is compromised and her capacity to attend is attenuated by fragmentation, we see an erosion of presence. 
By presenting Tamar's story, we have endeavored to illustrate a case of presence in teaching as it is defined by Rodgers \& Raider-Roth (2006) and the ways that disconnections in the relational web can undermine presence. Indeed, Tamar's pedagogical stories of connection illustrate the type of authentic engagement that demonstrates presence. However, we understand that the distraction of uncertainty surrounding Meir School (a new Head of School, economic crisis) was accompanied by the destabilization that Tamar experienced. Tamar's narrative presents a clear trail of evidence showing us the costs of an increasingly unhealthy relational context of this school.

\section{Implications}

The important implications of this study highlight the interconnected web of relationships within the school context that shape teachers' abilities to establish and maintain presence in teaching. In light of recent debates regarding educational transformation, this inquiry raises an important dimension for policy and decision making. Writing about the centrality of teachers in the blame game over failures in education, Cochran-Smith and Lytle (1999) point out the irony in placing the "blame" on teachers which "reinforced the idea that teachers could be powerful agents in the educational scene, able to make a difference by virtue of the decisions they made on a day-to-day basis" (p. 16). However, the narrative of blame stokes teachers' sense of vulnerability and threatens to destroy relational trust. In this unhealthy atmosphere the very relationships that support growth and resilience, and contribute to a teacher's presence, are strained and innovative teaching practices are compromised. Ultimately then, threats of sanctions against schools that focus on teachers' performance can actually produce an effect that is counter to their purported intentions. That is, rather than strengthening student learning, they reduce student learning as such contexts undermine presence.

The findings of this research add to the compelling body of evidence around the importance of "growth-fostering relationships" (Miller \& Stiver, 1997, p. 17), the way that such relationships support teachers' and learners' trust in their own knowledge (Raider-Roth, 2005; Raider-Roth, et al., 2008), and their willingness to take pedagogical risks (Stieha, 2010). Further, this paper contributes to others (e.g. Feiman-Nemser, 2008; Fullan, 2007b; Grossman \& McDonald, 2008) who have suggested that the contexts for teachers' professional lives are not inconsequential for their ability to support student learning. To sustain change, the entire system education-from student, teacher, administrator, school, district, and beyond — demand attention (Fullan, 2007b). Continued research with a relational lens needs to be conducted in order to understand the dynamics of relationships within and among the personal and professional systems within schools. The research discussed here seeks to focus attention on a particular teacher and her roles so that the complexity of these relational and contextual dynamics can be magnified and described. From this detailed discussion, we understand the centrality of creating school contexts that are rich with trust, respect, supported vulnerability, and mutuality. As we have seen through Tamar's stories, it is within these contexts that presence can thrive.

As we consider these implications we also note that there are important steps that teachers and administrators can take to help repair the areas of the relational web when they are stressed or compromised. Indeed, the relational literature emphasizes the importance of "repair" in developing and strengthening relationships (Gilligan, 2011; Raider-Roth, et al., 2012; Tronick \& Weinberg, 1997). Earlier we referenced the Reflective Seminar at Meir School, which Miriam led for two years, and we referenced Tamar's involvement in this group. In a series of sessions designed to focus the teachers' inquiry on their practice, the Reflective Seminar asked teachers to actively engage in examining their own teaching practice. They studied selected articles, formulated questions around their own teaching practice, and "conducted observations of their students and their learning" (Raider-Roth, 2008). Indeed, it was in these sessions that Tamar connected her own classroom experiences to her pedagogical struggles. During a "review of practice," Tamar began to unpack the overwhelming sense of being "fragmented" and "doing too much." In a sense her relationship with her teaching self appeared to be in jeopardy or fragmented. By describing her practice, and re-viewing her own work in a community of empathic and empowering relationships that the teachers found in the Reflective Seminar, Tamar was more able to reconnect with the aspects of teaching that sustained and energized her work. This learning community was a key to providing resilience and pushing back against some of the isolation and vulnerability the teachers felt in the school, a phenomenon that other researchers have described in similar professional development settings (Schultz, 2011). Although it is beyond the scope of this article to move deeply into the Reflective Seminar, it is important to highlight this initiative as a key to helping Tamar and the other teachers begin to repair some of the disconnections they were experiencing, and to find resilience in their collaborative reflection. It was a place where they could add a little bit of wind to their sails. 
Note: We would like to thank the anonymous reviewers whose careful critique was instrumental in shaping this article.

\section{References}

Achinstein, B. (2002). Conflict amid community: The micropolitics of teacher collaboration. Teachers College Record, 104(3), 421.

Adler, M., Rougle, E., Kaiser, E., \& Caughlan, S. (2003). Closing the gap between concept and practice: Toward more dialogic discussion in the language arts classroom. Journal of Adolescent \& Adult Literacy, 47(4), 312-322.

Ancess, J. (2000). The reciprocal influence of teacher learning, teaching practice, school restructuring, and student learning outcomes. Teachers College Record, 102(3), 590-619.

Anderson, T., Rourke, L., Garrison, D. R., \& Archer, W. (2001). Assessing teaching presence in a computer conferencing context. Journal of Asynchronous Learning Networks, 5(2), 1-17. Retrieved from http://auspace.athabascau.ca/bitstream/2149/725/1/assessing_teaching_presence.pdf

Aragon, S. R. (2003). Creating social presence in online environments. New Directions for Adult and Continuing Education, 100, 57-68.

Beauboeuf-Lafontant, T. (2009). Behind the mask of the strong black woman: voice and the embodiment of a costly performance: Temple University Press.

Bronfenbrenner, U. (1979). The ecology of human development: experiments by nature and design: Harvard University Press.

Brown, L. M., \& Gilligan, C. (1992). Meeting at the crossroads: Women's psychology and girls' development. New York: Ballantine.

Bryk, A. S., \& Schneider, B. (1996). Social trust: A moral resource for school improvement. Final deliverable to OERI: Wisconsin Center for Education Research, Madison

Bryk, A. S., \& Schneider, B. (2002). Trust in schools: A core resource for improvement. New York: Sage.

Bryk, A. S., \& Schneider, B. (2003). Trust in schools: A core resource for school reform. Educational Leadership, $60(6), 40-46$.

Cahnmann, M. (2003). The craft, practice, and possibility of poetry in educational research. Educational Researcher, 32(3), 29-36.

Chu, J. Y.-C. (2000). Learning what boys know: An observational and interview study with six four year-old boys. Unpublished Dissertation, Harvard University, Cambridge.

Clarke, A. E. (2007). Feminisms, grounded theory, and situational analysis. In S. Hesse-Beber (Ed.), Handbook of feminist research: Theory and praxis (pp. 345-370). Thousand Oaks, CA: Sage.

Cochran-Smith, M., \& Lytle, S. L. (1999). The Teacher Research Movement: A Decade Later. Educational Researcher, 28(7), 15-25.

Cochran-Smith, M., \& Lytle, S. L. (2009). Inquiry as stance: Practitioner research for the next generation. New York: Teachers College Press.

Cohen, D. K., \& Ball, D. L. (2001). Making change: Instruction and its improvement. Phi Delta Kappan, 83(1), 73.

Darling-Hammond, L., Hightower, A. M., Husbands, J. L., LaFors, J. R., Young, V. M., Christopher, C., et al. (2003). Building instructional quality: "Inside-out" and "outside-in" perspectives on San Diego's school reform. (A research report): Center for the Study of Teaching and Policy.

Dillon, L. (2010). Listening for voices of self: Digital journaling among gifted young adolescents. Qualitative Research Journal, 10(1), 13.

Doucet, A., \& Mauthner, N. S. (2008). What can be known and how? Narrated subjects and the Listening Guide. Qualitative Research, 8(3), 399-409.

Drake, P., \& Heath, L. (2008). Insider research in schools and universities. In P. Sikes \& A. Potts (Eds.), Researching education from the inside: Investigations from within (pp. 128-143). London: Routledge.

Estrella, K., \& Forinash, M. (2007). Narrative inquiry and arts-based inquiry: Multinarrative perspectives. Journal of Humanistic Psychology, 47(3), 376-383.

Feiman-Nemser, S. (2008). Learning to teach. In R. L. Goodman, P. A. Flexner \& L. D. Bloomberg (Eds.), What we now know about Jewish education: Perspectives on research for practice (pp. 213-221). Los Angeles: Torah Aura Productions.

Fessler, R. (1995). Dynamics of teacher career stages. In T. R. Guskey \& M. A. Huberman (Eds.), Professional development in education: New paradigms and practices (pp. 171-192). New York: Teachers College Press. 
Fitz, J. (2003). The politics of accountability: A perspective from England and Wales. Peabody Journal of Education, 73(4), 230-241.

Fullan, M. (2007a). Change the terms for teacher learning. Journal of Staff Development, 28(3), 35-36.

Fullan, M. (2007b). The new meaning of educational change. New York: Teachers College Press.

Gamoran, A., Secada, W. G., \& Marrett, C. B. (2000). The organizational context of teaching and learning: Changing theoretical perspectives. Handbook of the Sociology of Education, 37-63.

Gidseg, E. (2007). Standards, accountability, and the voices of experienced kindergarten teachers. University at Albany, SUNY, Albany, NY.

Gilligan, C. (1982). In a different voice: Psychological theory and women's development. Cambridge, MA: Harvard University Press.

Gilligan, C. (1996). The centrality of relationship in human development: A puzzle, some evidence, and a theory. In G. G. Noam \& K. W. Fischer (Eds.), Development and vulnerability in close relationships (pp. 237-261). Mahwah, NJ: Lawrence Erlbaum Associates.

Gilligan, C. (2002). Images of relationship The Jossey-Bass reader on gender in education (pp. 51-87). San Francisco: Jossey-Bass.

Gilligan, C. (2003). The birth of pleasure. New York: Vintage.

Gilligan, C. (2011). Joining the Resistance. Cambridge: Polity.

Gilligan, C., Spencer, R., Weinberg, M. K., \& Bertsch, T. (2003). On the listening guide: A voice centered relational method. In P. M. Camic, J. E. Rhodes \& L. Yardley (Eds.), Qualitative research in psychology: Expanding perspectives in methodology and design (pp. 157-172). Washington, D.C.: American Psychological Association.

Grossman, P., \& McDonald, M. (2008). Back to the future: Directions for research in teaching and teacher education. American Educational Research Journal, 45(1), 184-205.

Guskey, T. R. (2002). Professional development and teacher change. Teachers and Teaching: Theory and Practice, 8(3/4), 381-391.

Harding, S. (Ed.). (1987). Introduction: Is there a feminist method? Bloomington, IN: University of Indiana Press.

Hensley, B. (2009). The impact of campus climate on college choice. from ProQuest Dissertationss and Theses: http://search.proquest.com/docview/304850950?accountid=9649

Hesse, K. (1997). Out of the dust. New York: Scholastic.

Humphrey, C. (2007). Insider-outsider: Activating the hyphen. Action Research, 5(1), 11-26.

Huziak-Clark, T., Van Hook, S. J., Nurnberger-Haag, J., \& Ballone-Duran, L. (2007). Using inquiry to improve pedagogy through K-12/university partnerships. School Science \& Mathematics, 107(8), 311-324.

Jordan, J. V. (2001). A relational-cultural model: Healing through mutual empathy. Bulletin of the Menninger Clinic, 65(1), 92.

Koshoreck, J. W. (2004). Accountability and educational equity in the transformation of an urban district. In L. Skrla \& J. J. Scheurich (Eds.), Educational equity and accountability: Paradigms, policies and politics (pp. 155-174). NY: Rowman \& Littlefield Publishers.

Lam, Y. L. J. (2005). School organizational structures: effects on teacher and student learning. Journal of Educational Administration, 43(4), 387-401.

Lawrence-Lightfoot, S. (1997). A view of the whole: Origins and purposes. In S. Lawrence-Lightfoot \& J. H. Davis (Eds.), The art and science of portraiture (pp. 1-18). San Francisco, CA: Jossey-Bass.

Lieberman, A., \& Miller, L. (1999). Teachers-- Transforming their world and their work. New York: Teachers College Press.

Miller, J. B., \& Stiver, I. P. (1997). The healing connection: How women form relationships in therapy and in life. Boston, MA: Beacon.

Noddings, N. (2003). Caring: A feminine approach to ethics and moral education. Berkeley: University of California Press.

Patton, M. Q. (2002). Qualitative research and evaluation methods (3rd ed.). Thousand Oaks, CA: Sage Publications.

Patton, W. (2007). Connecting relational theory and the systems theory framework: Individuals and their systems Australian Journal of Career Development, 16(3), 38-46.

Peterson, P. L., McCarthey, S. J., \& Elmore, R. F. (1996). Learning from school restructuring. American Educational Research Journal, 33, 119-153.

Pianta, R. C., Stuhlman, M. W., \& Hamre, B. K. (2002). How schools can do it better: Fostering stronger connections between teachers and students, New Directions for Youth Development (Vol. 2002, pp. 91107): John Wiley \& Sons Inc. 
Raider-Roth, M. B. (2005). Trusting what you know: The high stakes of classroom relationships. San Francisco, CA: Jossey-Bass.

Raider-Roth, M. B. (2008). Annual report of the Center for Studies in Jewish Education and Culture. Cincinnati: University of Cincinnati.

Raider-Roth, M. B., Albert, M. K., Bircann-Barkley, I., Gidseg, E., \& Murray, T. (2008). Teaching boys: A relational puzzle. Teachers College Record, 110(2), 443-481.

Raider-Roth, M. B., \& Holzer, E. (2009). Learning to be present: How hevruta learning can activate teachers' relationships to self, other and text. Journal of Jewish Education, 75(3), 216-239.

Raider-Roth, M. B., Stieha, V., \& Hensley, B. (2012). Rupture and repair in the relational triangle: Veteran teachers, professional development and collaborative text study. Teaching and Teacher Education, 28, 493-502.

Reichert, M., \& Hawley, R. (2009). Reaching Boys. Phi Delta Kappan, 91(4), 35-40.

Reynolds, T., Murrill, L. D., \& Whitt, G. L. (2006). Learning from organizations: Mobilizing and sustaining teacher change. Educational Forum, 70(2), 123-133.

Rodgers, C. R., \& Raider-Roth, M. (2006). Presence in teaching. Teachers \& Teaching, 12(3), 265-287.

Sarason, S. B. (1996). Revising "the culture of school and the problem of change". New York, NY: Teachers College Press.

Schultz, K. (2011). Beginning with the Particular: Reimagining Professional Development as a Feminist Practice. The New Educator, 7(3), 287-302.

Sebring, P. B., Allensworth, E., Bryk, A. S., Easton, J. Q., Luppescu, S., \& Consortium on Chicago School Research, I. L. (2006). The Essential Supports for School Improvement. Research Report: Consortium on Chicago School Research.

Senge, P., Scharmer, C. O., Jaworski, J., \& Flowers, B. S. (2005). Presence: Exploring profound change in people, organizations and society. London: Nicholas Brealey Publishing.

Short, J. A., Williams, E., \& Christie, B. (1976). The social psychology of telecommuncations. London: Wiley.

Slater, J. J. (1996). Anatomy of a collaboration: Study of a college of education/public school partnership. New York: Garland Publishing.

Spencer, R. (2000). A comparison of relational psychologies. Wellesley, MA: Wellesley College.

Spencer, R., Porche, M. V., \& Tolman, D. L. (2003). We've come a long way -- maybe: New challenges for gender equity in education. Teachers College Record, 105(9), 1774-1807.

Stieha, V. (2010). The relational web in teaching and learning: Connections, disconnections and the central relational paradox in schools Retrieved from ProQuest Dissertations and Theses database Available from http://search.proquest.com.libproxy.boisestate.edu/docview/756900043?accountid=9649

Tappan, M. B. (2001). Interpretive psychology: Stories, circles and understanding lived experience. In D. L. Tolman \& M. Brydon-Miller (Eds.), From subjects to subjectivities: A handbook of interpretive and participatory methods (pp. 45-56). New York: New York University Press.

Timperley, H., \& Phillips, G. (2003). Linking teacher and studen learning adn professional learning to improve professional development in systemic reform. Teaching and Teacher Education, 19(6), 643-658.

Tronick, E. Z., \& Weinberg, M. K. (1997). Depressed mothers and infants: Failure to form dyadic states of consciousness. In L. Murray \& P. Cooper (Eds.), Postpartum depression and child development. New York: Guilford Press.

Tu, C. H., \& McIssac, M. (2002). The relationship of social presence and interaction in online classes. The American journal of distance education, 16(3).

Way, N. (2001). Using feminist reseach methods to explore boys' relationships. In D. L. Tolman \& M. BrydonMiller (Eds.), From subjects to subjectivities: A handbook of interpretive and participatory methods (pp. 111-129). NY: New York University Press.

Way, N. (2011). Deep Secrets: Boys' Friendships and the Crisis of Connection: Harvard University Press.

Way, N., \& Chu, J. Y.-C. (Eds.). (2004). Adolescent boys: Exploring diverse cultures of boyhood. New York: New York University Press.

Weasmer, J., Woods, A. M., \& Coburn, T. (2008). Enthusiastic and growing teachers: Individual dispositions, critical incidences, and family supports. Education, 129(1), 21-35. 